\title{
CUSTOMER PERCEPTION OF SERVICE QUALITY IN PUBLIC TRANSPORT
}

\author{
Dragana Grujičić, Ivan Ivanović, Jadranka Jović, Vladimir Đorić \\ Faculty of Transport and Traffic Engineering, University of Belgrade, Serbia
}

Submitted 4 July 2013; resubmitted 29 August 2013; accepted 18 October 2013

\begin{abstract}
This paper presents the research and analysis process showing that transport system customers have a specific perception of service quality, as an indicator of transport system. Determining satisfactory level of service quality implies knowledge of travel demand and travel behaviour. There are a lot of elements that define the transport system quality. The goal of this paper is to identify the public transport system's service quality elements that should be primarily acted on, in order to increase the level of service quality from transport system users' (public transport users' and non-users') point of view, with minimal investment. The paper describes a specifically defined research methodology for determining service quality elements that should be primarily acted on, from the transport system users' point of view. Methodology involves the use of Importance Performance Analysis (IPA) which is upgraded with the state preferences analysis. Presented methodology, which is used to determine user perception of service quality, can be considered to be universal. This methodology can be applied in other cities, with additional research that must precede its use. The methodology was tested on transport system users in Belgrade.
\end{abstract}

Keywords: travel behaviour; service quality; public transport; customer satisfaction; mode choice.

Reference to this paper should be made as follows: Grujičić, D.; Ivanović, I.; Jović, J.; Đorić, V. 2014. Customer perception of service quality in public transport, Transport 29(3): 285-295. http://dx.doi.org/10.3846/16484142.2014.951685

\section{Introduction}

Knowledge of customer behaviour when choosing transport mode is a significant subject of studies by transport experts. The answer to the question what customers consider as a quality of transport system and what indicators can be used to represent it varies for different level of society development, different socioeconomic population categories and the transport system itself. From a historic perspective, the oldest, and in some undeveloped society still the most significant indicator of transport system quality, is the existence of capacities (infrastructure, public transport lines, railway, etc.) i.e. the capacity to satisfy transport demand within the required period of time, in a given direction. Other significant parameters include travel time, reliability, comfort, safety, economy, environmental impact, accessibility, etc. (Jović 1992).

There are a large number of factors that influence customers, when choosing mode of transport. One of the factors that influence a choice of transport mode is, for example, user's travel expenses. This paper focuses on the research of customer perception of public transport service quality. Quality of service is the overall measured or perceived performance of transport system service from the passenger's point of view (TRB 2003). Service quality elements can be classified into several groups: vehicle elements, transport system elements and human factor elements.

Customers perceive each of the service quality elements in a different way. The same quality of service element can be judged differently by different customers in terms of level of satisfaction and importance. Analysing the satisfaction level and importance level of service quality elements from the customers' point of view, service quality elements with a high level of importance and a low level of satisfaction can be identified. With the aim of improving the quality of the transport system from the customers' point of view, those elements should be acted on.

If transport system customers are highly satisfied with certain service quality elements, in time the quality level of the given element starts to be implied and customers start to be highly sensitive to the changes in it. For example, if a public transport line is introduced to a non-serviced part of the city, for the local resident customer perception of transport system, the service quality

Corresponding author: Jadranka Jović

E-mail: j.jovic@sf.bg.ac.rs 
is changed by the existence of the line. In the case of the resident of the part of the city that has public transport system service, dissatisfaction is expressed in the event of the vehicle delay of several minutes.

The goal of this paper is to find a way to improve the public transport system service quality from users and non-users point of view, with minimal investment. Authors want to find service quality elements whose improvement, to the greatest extent, can contribute improving the quality of the public transport system from the users' point of view. One of the strategic objectives of the transport system in Belgrade is to attract new users to public transport and relieve the transport network of passenger car users. Authors started from the assumption that the improvement of the previously mentioned elements will affect on attracting new users, and they wanted to determine precisely those elements that would affect the improvement of public transport service quality from the users' and non-users' point of view.

Identifying the inefficiencies of the public transport system will help with improving service management, expanding coverage and increasing the attractiveness of public transport services. The key to providing effective customer service is the accurate determination of the customer's needs and response to them in a consistent manner in order to assure their satisfaction.

Just because not all elements of service quality are equally important for the customer, acting on different elements does not achieve the same effect of improving the quality of the system. To identify the service quality elements which improvement would largely contribute upgrading the user's perception of the transport system quality, it is necessary to know the user's behaviour.

In order to assess the level of importance and the level of customer satisfaction with service quality elements, specific research has been done. A survey of service quality elements in public transport system was carried out during spring period of 2011 in Belgrade. The aim of this survey was to obtain information on customer satisfaction level for each of the 24 service quality elements on one hand, while on the other hand the importance of each service quality element was investigated.

For identifying the service quality elements that should be acted on primarily, in order to improve the quality of the public transport system from customers' point of view, a particular methodology is presented.

The results of this paper are related to the observed area and the state of the public transport system in Belgrade, while the methodology can be considered to be universal. This paper showed that implementation of certain methods can determine and quantify customers' understanding of the notion of service quality. This study allows for implementation of behavioural analysis in engineering procedures.

Literature review from the field of measurement and understanding of customer satisfaction with services, as well as from the field of factors affecting transport mode choice, is presented in the first part of the paper.
Results of survey on customer perception of the public transport's service quality in Belgrade are presented in the second part of the paper. Each of the analysed service quality elements, the level of importance and level of satisfaction, perceived by the user, were examined.

Proposed methodology is presented in the third part of the paper. Authors propose methodology that includes combination of importance performance analysis upgraded with confidence intervals and state preference analysis. Confidence intervals are used in order to make IPA more effective. Further, the proposed methodology involves the application of the state preference analysis. This analysis contributes to the goal of this paper. After conducting this analysis authors will be able to determine which elements should be primarily improved.

In the fourth part of the paper the results of detailed analysis are presented. Out of 24 elements, those that seem to be priority, in order to improve the system quality from the transport system users' point of view, are identified.

\section{Literature Review}

Extensive literature on measurement and understanding of customer satisfaction with services has been developed.

Parasuraman et al. (1985) emphasized that attainment of quality in products and services has become a pivotal concern of the 1980s. In that period, quality in service was largely undefined and unexplored.

Jović (1992) carried out the first survey of indicators that customers used to define the notion of public transport system service quality in Belgrade. The goal of this survey was to determine what transport system customers consider to be service quality. The survey showed that customer perception of service quality implied all of the elements in the functioning of the transport that customers were dissatisfied with. Service quality elements established in this research, among others, were used in research that authors conducted during 2011.

Gotlieb et al. (1994) in their article applied a theoretical framework to help building a model that attempted to explain the relationships among disconfirmation of expectations, perceived quality, satisfaction, perceived situational control, and behavioural intentions. The results of the study suggested that the focal and contextual dimensions of disconfirmation of expectations affected perceived quality enroute to their influence on behavioural intentions. Additionally, the results indicated that perceived quality affected satisfaction which as a result affected behavioural intentions.

Lai and Chen (2011) highlighted behavioural intentions and explored the relationships between passenger behavioural intentions and the various factors that affect them. Apart from the factors recognized by past studies, such as service quality, perceived value, and satisfaction, this study addressed the importance of the involvement of public transit services in passenger behavioural intentions. According to their results, service attributes such as vehicle safety, facility cleanliness, and complaint 
handing have significant influences on passenger behavioural intentions.

Dell'Olio et al. (2010) showed that perception of quality changed with the category of user and that there tended to be more criticism towards variations in overall quality until the users were stimulated into thinking more deeply about other influential variables. Although, the aim of survey that Olio presented was very similar with the aim that authors presented, methodologies were quite different. Also, the difference between researched transport systems contributed to different obtained results. For example, cleanliness of the bus had no relevant weight in Olio's study. The weight given to vehicle cleanliness was negligible because the bus fleet in the city where survey was conducted had only recently been completely renewed, with no vehicles over 2 years old. Therefore, the user did not value lack of cleanliness because they were completely satisfied in this respect. This was not the case in the survey results obtained in Belgrade, and that was logical because the average age of vehicles was more than 11 years.

Dell'Olio et al. (2011) highlighted that desired quality is different from the perceived quality because it does not represent the daily experiences of the users, but rather what they desire or hope for from their public transport system. Waiting time, cleanliness and comfort are shown to be the public transport variables that users most valued, but the degree to which they are valued varies according to the category of a user. Variables such as driver kindness, bus occupancy and journey time are generally given less weight. For potential users the more important variables when defining expected quality from public transport are waiting time, journey time and above all, level of occupancy. The purpose of the research, conducted by authors in Belgrade, was also to improve transport system service quality based on users and potential users' perception.

There is also an extensive literature on the subject of factors affecting transport mode choice.

Watson (1974) noted that the customers chose the mode of transport by assigning each criterion a specific weight, i.e. they evaluated each of the criteria in their own way. The passenger will choose the mode of transport whose speed, costs and comfort, weighted by the importance that the passenger assigns to each of the criteria, represent the best combination compared to other modes of transport. Weight is determined by the characteristics of the passenger, their environment and trip purpose that are being undertaken. It is assumed that the customer is rational, i.e. that they want a faster, cheaper and more comfortable trip, that the customer's resources are limited, that they are aware of the characteristics of the mode of transport that are the subject of the selection, that the choice of means of transport will always be the same under unchanged circumstances, and that the choice was made based on the characteristics of the mode of transport, own characteristics and trip characteristics.

Jović (2000) emphasized that the users' mode selection was not a static or accidental process. Namely, real time, space and quality were not understood by all user groups in the same way. Thus, the users' acceptance or refusal to select a specified mode does not depend only on real (engineering) parameters but, to a much greater extent, on the value of these parameters as determined by the users. For realistic planning it is necessary to know the users' response which varies in time and depends on the given circumstances, due to which it must be determined a new one for each district.

Zhao et al. (2002) classified factors that affecting public transport usage into four categories: a travel mode Level Of Service (LOS); accessibility; land use and public transport users' socioeconomic characteristics. Characteristics of a trip (for instance the trip purpose and the trip distance) also may affect the mode of travel. Many of the LOS factors affecting public transport use, however, cannot be easily quantified and there is always the problem of generally not having available data.

Beale and Bonsall (2007) in their research aimed to explore the extent to which the low and declining use of bus services reflected overly negative public perceptions of buses and whether, if key misperceptions could be corrected by persuasive messages, people might change their attitudes towards bus travel and increase their use of bus services. They suggested that, to avoid adverse impacts on people's bus use, the message content and target audience should be carefully considered. Their results emphasized the need to consider the different responses likely to come from different subgroups within a target audience. Their findings indicated the need to consider the different attitudes, beliefs, self-images, aspirations and ways of thinking and processing information that characterised different groups of potential users.

Chen and Chao (2011) emphasised that it was more difficult to break or reduce private vehicle use for individuals with a strong private vehicle use habit than those with a weak habit, because a strong habit to use a particular travel mode sought less information and a less elaborate choice of travel mode.

There is a large number of papers dealing with customer satisfaction and choice of the transport mode. Papers which are similar in terms of aim and scope, with research conducted in Belgrade, are primarily listed in the literature review. Presented papers analyse service quality elements in a similar way and also analyse which service quality elements have the greatest influence on the choice of the transport mode. In this way similarities and differences between research conducted by authors and the relevant research in the world is presented.

\section{Survey of Belgrade Public Transport System's Service Quality}

Belgrade, the biggest city on Balkan Peninsula, is the capital of Serbia with approximately 1.5 million inhabitants. It represents a significant traffic node in the region. Belgrade urban area is about $360 \mathrm{~km}^{2}$. During year 2011, the total number of public transport lines in daily transport in Belgrade was 139. Total length of public transport network lines was $1887 \mathrm{~km}$. Average number of vehicles 
in inventory was 1174 vehicles. Inclusive with 2011, age structure of inventory fleet was 11.64 years ( $h t t p: / / w w w$. gsp.rs/english/statistic.htm). Such a public transport system served a quite developed network. This fact should be kept in mind in order to understand obtained results.

Survey of service quality elements in public transport system was conducted at fifteen bus stops on the Belgrade territory. Eight stops in the central city area and seven stops in the wider urban area were selected. That included users of different lines in order to obtain a comprehensive assessment of the public transport system from the public transport users' point of view. The first part of survey was related to respondents' age, sex, employment, vehicle ownership etc. In the second part of the survey respondents gave separate scores for each of the defined variables (Table 1) in terms of importance and satisfaction. The list of service quality elements can be developed after review of relevant literature, conducting focus group interviews, and using managerial judgment.

Public transport service quality may be considered in terms of passenger comfort, cleanliness and appearance, safety and security, hours of service, reliability, service coverage, cost, parking spaces etc. Some of these are traditional levels of service variables (frequency, route coverage, fares) while others have been recently included as a transit level of service factors (Kittelson \& Associates, Inc. 1999; Ryus et al. 2000).

Authors made the list of 24 service quality element based on the relevant literature. Some of those elements are travel time, punctuality, passenger politeness, vehicle age, cleanliness in the vehicle, driving safety and security etc. All 24 elements are specified in Table 1.

One service quality element that is not within these 24 elements, although it is very important, is accessibility for people with disability. For a long time, developed countries work on so-called barrier-free transport. In Belgrade this problem still exists and it does not seem that it will soon be solved mainly because of economic issues. People with disabilities in Belgrade unfortunately do not have equal status in society and consequently they do not have equal status in public transport. There is a historical problem in the fields of planning, designing and building (infrastructure and vehicles) because accessibility principles were not followed. The result is the fact that small number of persons with disabilities uses public transport. In Belgrade there is a special service for transport of disabled persons which functions as door to door transport. People with disabilities would be the most relevant to evaluate the accessibility, but it was not possible to survey them at the bus stops. Because of that authors did not include this service quality element in the list. Authors' opinion is that 'accessibility for people with disability' is important service quality element and it should be investigated through some of the next research that should include disabled persons.

For the 24 elements of service quality determined in this study, customers provided an assessment of the level of satisfaction and the level of element importance. The users gave grades from 1 to 5 to each element. Type of Likert scale that is used is as follows: 1 - not at all satisfied/important, 2 - slightly satisfied/important, 3 moderately satisfied/important, 4 - very satisfied/important, 5 - extremely satisfied/important.

The survey covered 463 respondents and the sample was random. As previously mentioned, survey was done on bus stops and because of that 96\% (449 respondents) of respondents were hard core public transport users. This group of respondents was the subject for further analyses. There were 55\% male and $45 \% \mathrm{fe}$ male. Observed by the age group, respondents between 18 and 25 years were most represented in the sample, because younger people rather have participated in the survey. Other groups were balanced, except the age group above 65 years which represented only one per cent of a sample. In total number of respondents $46 \%$ were students, $39 \%$ were full-time employees, $10 \%$ were occasionally employed, and 5\% were unemployed. When asked whether they own a passenger vehicle, $62 \%$ of the respondents answered positively, while $38 \%$ stated that they do not own a passenger vehicle.

Table 1 presents the results, where 449 respondents were polled about the level of importance and level of satisfaction with service quality elements. The values next to the service quality element labels represent the number of respondents that ranked the given service quality element with the corresponding grade.

The $S$ (satisfaction i.e. performance) and $I$ (importance) value for each service quality element is computed by the average grade from all public transport users. The $S$ and $I$ value for element $i$ are computed:

$$
\begin{gathered}
S_{i}=\frac{\sum_{j=1}^{n} y_{i j}}{n} ; \\
I_{i}=\frac{\sum_{j=1}^{n} x_{i j}}{n},
\end{gathered}
$$

where: $y$ - the grade for satisfaction; $x$ - the grade for importance; $i$ - ordinal number of service quality element $(i=1,2,3, \ldots, 24) ; j$ - ordinal number of public transport user $(j=1,2,3, \ldots, n) ; n$ - number of public transport users $(n=449)$.

\section{Methodology}

The Importance-Performance Analysis (IPA) (Martilla, James 1977) is an integral part of the research techniques that include analysis of customer views on the main attributes of products and services.

The indicators provided by the IPA are very useful for detailed analysis of the difference that exists between the expected and real state, as well as for determining areas where improvements are possible. The IPA is used in the process of determining and generalizing elements of service quality, with the aim of identifying the key elements of service quality that require improvement. The purpose of the IPA is to point out the areas where improvements would have the greatest impact on improving satisfaction with the entire system (Yang et al. 2011). 
Table 1. Level of satisfaction and importance of service quality elements

\begin{tabular}{|c|c|c|c|c|c|c|c|c|}
\hline \multirow{2}{*}{\multicolumn{2}{|c|}{ Level of satisfaction }} & \multicolumn{6}{|c|}{ Number of respondents who specified grade } & \multirow{2}{*}{$S$} \\
\hline & & Grade: & 1 & 2 & 3 & 4 & 5 & \\
\hline 1 & Enough place in the vehicle & & 134 & 205 & 67 & 38 & 5 & 2.05 \\
\hline 2 & Getting a seat & & 66 & 192 & 131 & 58 & 1 & 2.41 \\
\hline 3 & Absence of noise in vehicle & & 55 & 149 & 169 & 70 & 5 & 2.60 \\
\hline 4 & Music in the vehicle & & 63 & 96 & 208 & 69 & 13 & 2.72 \\
\hline 5 & Fellow traveller cleanliness & & 102 & 163 & 103 & 68 & 11 & 2.38 \\
\hline 6 & Passenger politeness & & 61 & 147 & 135 & 91 & 15 & 2.67 \\
\hline 7 & Driver and controller cordiality & & 43 & 85 & 141 & 148 & 31 & 3.09 \\
\hline 8 & Information provision & & 54 & 117 & 90 & 152 & 36 & 3.00 \\
\hline 9 & Vehicle age & & 60 & 182 & 126 & 77 & 4 & 2.52 \\
\hline 10 & Cleanliness in the vehicle & & 78 & 185 & 94 & 77 & 13 & 2.47 \\
\hline 11 & Ventilation in the vehicle & & 63 & 189 & 101 & 84 & 11 & 2.53 \\
\hline 12 & Air conditioning in the vehicle & & 70 & 159 & 155 & 57 & 8 & 2.50 \\
\hline 13 & Vehicle suitability & & 27 & 59 & 231 & 87 & 15 & 2.94 \\
\hline 14 & Protection from exposure to the elements & & 26 & 56 & 100 & 216 & 49 & 3.46 \\
\hline 15 & Tickets price & & 137 & 128 & 80 & 79 & 24 & 2.39 \\
\hline 16 & Possibility of finding a parking place & & 73 & 114 & 178 & 32 & 13 & 2.50 \\
\hline 17 & Waiting time at stop & & 73 & 172 & 83 & 107 & 13 & 2.59 \\
\hline 18 & Avoidance of traffic jam & & 65 & 163 & 122 & 85 & 12 & 2.59 \\
\hline 19 & Pavement quality & & 86 & 152 & 124 & 76 & 10 & 2.49 \\
\hline 20 & Travel time & & 55 & 154 & 84 & 138 & 17 & 2.79 \\
\hline 21 & Punctuality & & 75 & 134 & 113 & 113 & 14 & 2.68 \\
\hline 22 & Vehicle frequency & & 43 & 146 & 96 & 120 & 14 & 2.79 \\
\hline 23 & Driving safety and security & & 23 & 73 & 105 & 202 & 44 & 3.38 \\
\hline 24 & Appropriateness of speed & & 26 & 62 & 111 & 207 & 43 & 3.40 \\
\hline \multirow{2}{*}{\multicolumn{2}{|c|}{ Level of importance }} & \multicolumn{6}{|c|}{ Number of respondents who specified grade } & \multirow{2}{*}{$I$} \\
\hline & & Grade: & 1 & 2 & 3 & 4 & 5 & \\
\hline 1 & Enough place in the vehicle & & 6 & 10 & 91 & 157 & 184 & 4.12 \\
\hline 2 & Getting a seat & & 32 & 86 & 126 & 123 & 82 & 3.30 \\
\hline 3 & Absence of noise in vehicle & & 24 & 73 & 151 & 114 & 87 & 3.37 \\
\hline 4 & Music in the vehicle & & 129 & 111 & 119 & 50 & 40 & 2.47 \\
\hline 5 & Fellow traveller cleanliness & & 11 & 18 & 61 & 151 & 208 & 4.17 \\
\hline 6 & Passenger politeness & & 3 & 16 & 63 & 137 & 228 & 4.28 \\
\hline 7 & Driver and controller cordiality & & 11 & 24 & 67 & 152 & 194 & 4.10 \\
\hline 8 & Information provision & & 6 & 14 & 50 & 130 & 247 & 4.34 \\
\hline 9 & Vehicle age & & 11 & 54 & 137 & 149 & 98 & 3.60 \\
\hline 10 & Cleanliness in the vehicle & & 2 & 11 & 48 & 170 & 218 & 4.32 \\
\hline 11 & Ventilation in the vehicle & & 3 & 14 & 51 & 138 & 242 & 4.34 \\
\hline 12 & Air conditioning in the vehicle & & 8 & 31 & 158 & 156 & 95 & 3.67 \\
\hline 13 & Vehicle suitability & & 65 & 96 & 123 & 96 & 69 & 3.02 \\
\hline 14 & Protection from exposure to the elements & & 3 & 12 & 50 & 145 & 238 & 4.35 \\
\hline 15 & Tickets price & & 4 & 8 & 51 & 112 & 273 & 4.43 \\
\hline 16 & Possibility of finding a parking place & & 44 & 18 & 60 & 101 & 187 & 3.90 \\
\hline 17 & Waiting time at stop & & 2 & 3 & 21 & 149 & 273 & 4.54 \\
\hline 18 & Avoidance of traffic jam & & 4 & 8 & 56 & 174 & 207 & 4.27 \\
\hline 19 & Pavement quality & & 0 & 48 & 98 & 131 & 160 & 3.92 \\
\hline 20 & Travel time & & 0 & 9 & 54 & 176 & 207 & 4.30 \\
\hline 21 & Punctuality & & 1 & 9 & 28 & 122 & 289 & 4.53 \\
\hline 22 & Vehicle frequency & & 2 & 7 & 27 & 154 & 259 & 4.47 \\
\hline 23 & Driving safety and security & & 1 & 6 & 37 & 83 & 322 & 4.60 \\
\hline 24 & Appropriateness of speed & & 17 & 28 & 81 & 134 & 189 & 4.00 \\
\hline
\end{tabular}


In practice IPA helps determined parameters of products or services that are priorities for improvement and therefore allow for the implementation of direct strategies that are based on the improvement of quality (Joppe et al. 2001; Eskildsen, Kristensen 2006; Wu, Shieh 2009).

The IPA identifies strengths and weaknesses by comparing the two criteria that consumers use in making a choice. The first criteria is the relative importance of attributes (reflection of the relative value of the various quality attributes to consumers) and the second is satisfaction (consumers' evaluation of the offering in terms of those attributes) (Slack 1994).

Beside IPA there is a SERVQUAL method which also is able to explain significant amount of service quality. The measurements of the IPA and the SERVQUAL model are quite similar. The service quality factors of IPA model, however, had more comprehensive consideration in comparison to those of SERVQUAL (Haeryip et al. 2012).

Using the IPA it is possible to identify parameters that are most important to the customer, as well as those that have poor performance, i.e. the parameters that should be immediately improved (Matzler et al. 2003; Deng et al. 2008). The IPA is presented as a two-dimensional matrix in the coordinate system ( $x$-axis importance, $y$-axis satisfaction (performance)), which forms four quadrants. The cells of the matrix are customarily defined by the average values of the evaluation of all attributes, related to importance as well as to the evaluation of the quality attribute (performance), and then two lines are defined, parallel to the two axes (the importance-axis and the performance-axis), in the points of the average values of the evaluation of importance and evaluation of performance of all the attributes, in total. The quadrants are referred to by the names in some literature: QI Keep up the good work, QII Possible overkill, QIII Low priority, and QIV Concentrate here (Deng et al. 2008; Wu, Shieh 2009) (Fig. 1).

Boundaries between quadrants are:

$\bar{S}=\sum_{i=1}^{k} \frac{S_{i}}{k}$, mean value of all items'

performance (satisfaction);

$$
\bar{I}=\sum_{i=1}^{k} \frac{I_{i}}{k} \text {, mean value of all items' importance. }
$$

The attributes located in Quadrant QI have both great importance and high level of performance, and they are perceived as parameters that can be used to achieve or maintain competitiveness, and the functioning of these components should be maintained at the existing level. Quadrant QII contains attributes that have high performance but low importance, which indicates that resources assigned to these attributes are too great and that they should be assigned to some other attributes. Quadrant QIII contains attributes that feature both low importance and low performance, and therefore these attributes do not require any additional effort. At-

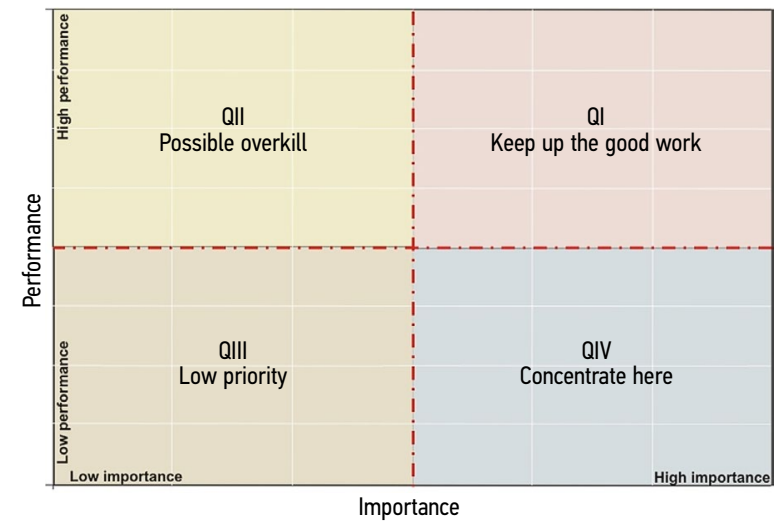

Fig. 1. Quadrants in IPA

tributes in Quadrant QIV are of great importance but have poor performance (low customer satisfaction), and are therefore considered attributes of the greatest weakness and should be improved. This is why it is necessary to urgently improve these attributes.

The inability to identify the attributes in Quadrant QIV might result in low customer satisfaction. Immediate improvement efforts should be placed in the highest priority when major weaknesses are identified, while attributes in Quadrant QI regarded as major strengths should be maintained, leveraged, and heavily promoted (Deng et al. 2008; Wu et al. 2010).

The authors of this study chose a methodology that upgrades IPA with confidence interval in order to make IPA more effective. Level of importance and satisfaction for a particular item determine where in coordinate system an item is located. If decision makers use only point estimates for items, they might be mistaken. $\mathrm{Wu}$ and Shieh (2009) introduced the philosophy of using confidence intervals to make IPA more effective in judging any item located in this two-dimensional grid. Confidence intervals integrated with IPA enables the decision maker much easier to identify the strengths and weaknesses based upon the sample of size used.

Confidence intervals show the range in which the population parameter is likely. The specified probability is called the confidence level. In applied practice, confidence intervals are typically stated at the $95 \%$ confidence level. The desired level of confidence is set by the researcher (not determined by data). Confidence interval of $95 \%$ means that there is $95 \%$ confidence level that the similarly constructed interval will contain the parameter that is to be estimated. The confidence interval is numerical interval in which we expect to find the parameters of the basic set based on of sample parameters for a given probability and its corresponding $z$-value.

Equation for confidence interval calculating is:

$$
\bar{X} \pm z_{\alpha / 2} \frac{\sigma}{\sqrt{n}}
$$

where: the value of $Z_{\alpha / 2}$ is dependent upon what confidence level a decision maker is interested, $\bar{X}$ is the sample mean; $\frac{\sigma}{\sqrt{n}}$ is standard error of the mean. 
After the formation of confidence interval, the last step of proposed methodology is state preference analysis. State preference analysis aims to determine the extent to which the elements that should be acted on, in order to improve the satisfaction of public transport users, match those elements whose improvement would affect the current non-users to choose public transport. After conducting state preference analysis authors will be able to determine which elements should be primarily acted on, in order to improve the public transport system's service quality from transport system users' point of view, with minimal investment.

\section{Identification of Service Quality Elements That Should Be Primarily Acted On}

The service quality elements are distributed in the coordinate system, with the $x$-axis representing the importance of the service quality element for the customer, while the $y$-axis represents customer satisfaction with the service quality element. The coordinates of each of the presented elements consisted of the average rating of element importance ( $x$-axis) and the average rating of customer satisfaction obtained from the respondents ( $y$-axis) (Table 1). Each item is represented by a pair of values (for item $i: I_{i}, S_{i}$ ). The service quality elements are represented by numbers 1 through 24 . The numeration of the service quality elements is taken from Table 1.

In the previous text it, was reported that the respondents provided ratings from 1 to 5 , however due to the range of the obtained results, and for better clarity, the coordinate system axes are shown using different ranges (Fig. 2).

Table 2 displays service quality elements that were singled out as very important and for which customer satisfaction is very low (lower-right quadrant, Quadrant QIV). The greatest improvement in customer satisfaction with the functioning of the public transport system and entire transport system would be achieved by improving service quality elements in the Quadrant QIV.

Results of the surveyed sample showed that acting on listed elements is the best way for improving the Belgrade public transport system quality, from the users' point of view. However, the question is, whether the testing of new sample will obtain identical results. For example, in presented case, elements 6 and 21 are in Quadrant QIV, but very close to Quadrant QI. If vari-

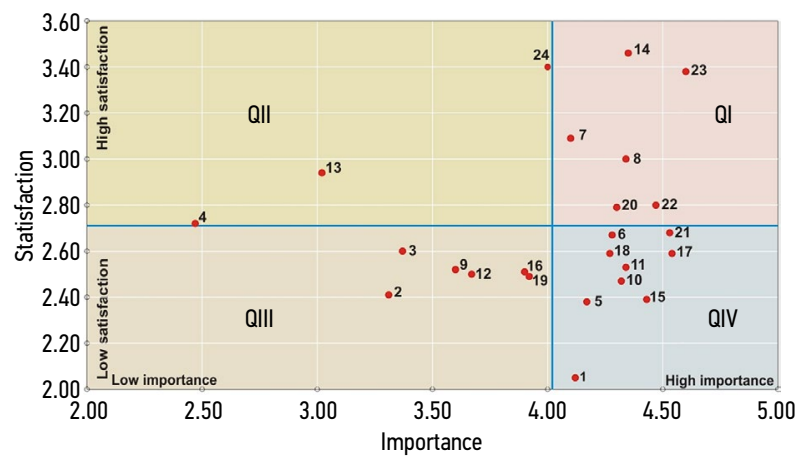

Fig. 2. Service quality elements distributed per quadrants
Table 2. Service quality elements that need to be improved

\begin{tabular}{cl}
\hline No & \multicolumn{1}{c}{ Service quality element } \\
\hline 1 & Enough place in the vehicle \\
\hline 5 & Fellow traveller cleanliness \\
\hline 6 & Passenger politeness \\
\hline 10 & Cleanliness in the vehicle \\
\hline 11 & Ventilation in the vehicle \\
\hline 15 & Tickets price \\
\hline 17 & Waiting time at stop \\
\hline 18 & Avoidance of traffic jam \\
\hline 21 & Punctuality \\
\hline
\end{tabular}

ability of sample is taken into account, these elements may be located in Quadrant QI, and consequently not represent elements that decision makers should improve.

To avoid a mistake in selecting service quality elements that should be primarily acted on, confidence interval will be introduced. Confidence interval of $95 \%$ is applied, and result of the application is shown in Fig. 3.

Elements that are within the confidence interval can be seen in Fig. 3. It is assumed that in the case of IPA on a new sample, some of these elements can be located in one of the adjacent quadrants. Elements that have the potential to get in the Quadrant QIV, are elements 20 (Travel time), 22 (Vehicle frequency), 16 (Possibility of finding a parking place) and 19 (Pavement quality) because there are located in confidence interval.

It can also be seen that the elements 1 (Enough place in the vehicle), 5 (Fellow traveller cleanliness), 6 (Passenger politeness), 17 (Waiting time at stop), 18 (Avoidance of traffic jam) and 21 (Punctuality) are in the confidence interval, which means that there is a possibility that a new sample analysis will not assign these elements in the Quadrant QIV. Three elements that are located in Quadrant QIV, regardless of the confidence intervals settings, are 11 (Ventilation in the vehicle), 10 (Cleanliness in the vehicle) and 15 (Tickets price). It means that regardless of the sample choice these three elements will remain in Quadrant QIV with a probability of $95 \%$.

Probably the high temperatures in the period when the survey was conducted, and a large number of defective air conditioning device in public transport vehicles

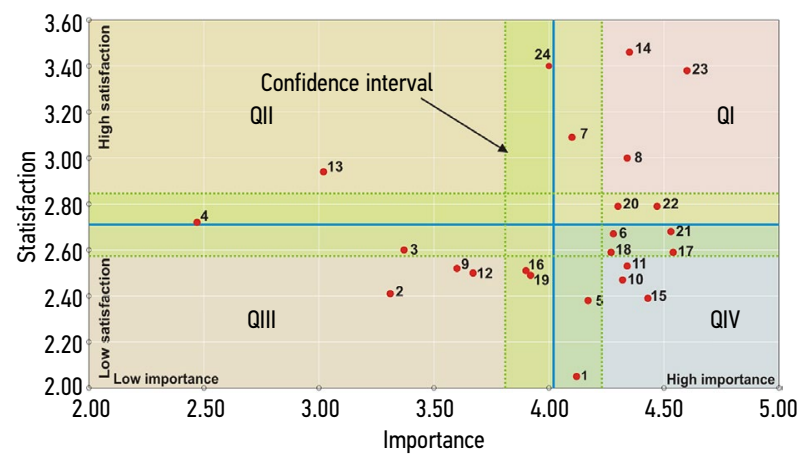

Fig. 3. Introduction of confidence interval 
are the reason why the service quality element 11 is among these three elements. In the case of service quality element 10 average vehicle age of 11.64 years and inadequate maintenance of vehicles may be the reason why this element is found among these three elements, while in the case of the element 15 , poor economic situation in the country as well as the high unemployment rate might be responsible.

According to this analysis, if decision makers want to improve the public transport users' satisfaction level they should act primarily on these three elements. Identification of these elements can be very important, especially if there are some financial constraints which prevent acting on large number of service quality elements.

The question is whether the improving of identified public transport service quality elements can contribute to strategic objectives of whole transport system. One of the goals of the transport system is to retain the existing public transport system users and attract new users to public transport.

Service quality has great influence on modal split. User's decision about transport mode choice often depends on quality of supply. Some papers which verify this are presented in literature review. Factors such as service quality, consumer satisfaction, and value are frequently viewed as key building blocks of customer loyalty (Chen 2008). Those who have access to a personal vehicle are expected to weigh the benefits of taking public transport relative to the convenience of driving. The use of the public transport system by those who have no private vehicles and to a much larger extent those who have vehicles, depends on the level of service (Zhao et al. 2002).

The previous analysis cannot confirm with certainty whether the improvement of the identified elements contribute to the achievement of above mentioned goal. The above analysis is related only to the public transport users, while examining opportunities to attract new users requires the survey of public transport non-users. By comparing the results obtained by surveying users and non-users it is possible to determine service quality elements which improvement will effect on improvement of public transport quality perception in both categories.

In order to get the answer to that question the state preference analysis of passenger car users is conducted. Stated preference methods refer to a family which uses individual respondents' statements about their preferences in a set of transport options to estimate utility functions. The options are typically descriptions of transport situation or contexts constructed by the researcher. Stated preference methods require purpose designed surveys for their collection of data (Kroes, Sheldon 1988).

The aim of the state preference analysis of passenger car users is to identify the service quality elements which improvement has the greatest effect in increasing preference of respondents to shift to public transport. This analysis does not provide an indicator of what percentage of users would transfer from passenger vehicles to public transport in the event of the improvement of certain elements. The analysis only identifies the elements whose improvement would contribute most of all to the transfer of passenger car users to public transport.

The study was conducted on 180 respondents who were passenger car users. The question that was posed to them was related to their preference for switching to use the public transport system in the case when any of the above mentioned service quality elements had improved to a satisfactory level. The respondents rated each of the 24 service quality elements on a scale of 1 to 10 , expressing their preference to make the shift from passenger vehicles to public transport, in the event of the improvement of a certain service quality element to a satisfactory level. For example, question nine was, 'Quantify your intention (from 1 to 10 ) for transferring from passenger car to public transport in case of public transport vehicles regeneration'.

In this case it was not important to examine what was the acceptable level of improving service quality elements for each user, because of the assumption that each of the respondents had different criteria. It was important to identify the service quality elements which respondents rated with the highest preference to switch to public transport system in the case of their improvement.

Table 3 presents only the nine best ranked service quality elements based on mean values of respondents' preferences.

Only the first nine elements are shown because the IPA before introduction of confidence interval identified nine service quality elements whose improvement could raise the quality of public transport system from the users' point of view, the elements from the Quadrant QIV. In this way it is possible to compare the results obtained in both analysis and determine whether there is overlapping of service quality elements that should be acted on. Based on the comparison of results it can be seen that there is a match in 7 out of 9 elements (Table 4).

The result of the state preference analysis gives two elements which are not found in the IPA in a Quadrant QIV. These are service quality element 20 (Travel time) and 22 (Vehicle frequency). This mismatch was expected because it was a different category of respondents. For passenger car users travel time and vehicle frequency are very important as can be seen from their position in the table. The fact that the elements 20 and 22 are within the confidence interval in IPA means that there is probability that these elements are found in Quadrant QIV in the examination of a some other sample of respondents.

The IPA was found that next to the seven elements that coincide with the results of the state preference analysis in Quadrant QIV are elements 15 (Tickets price) and 6 (Passenger politeness). These two elements are not ranked in the top 9 service quality elements in the state preference analysis. Since in the state preference analysis passenger car users were surveyed it was expected for element 15 (Tickets price) not to be identified as one of the key criteria for the transition to the using public transport. Costs of using passenger cars, however, are much higher than the cost of using public transport. An- 
Table 3. Average preference values obtained for service quality elements

\begin{tabular}{clcc}
\hline No & Service quality element & Mean & $\begin{array}{c}\text { Standard } \\
\text { Deviation }\end{array}$ \\
\hline 21 & Punctuality & 8.33 & 1.83 \\
\hline 20 & Travel time & 8.23 & 1.82 \\
\hline 22 & Vehicle frequency & 8.20 & 1.76 \\
\hline 10 & Cleanliness in the vehicle & 8.18 & 2.04 \\
\hline 17 & Waiting time at stop & 8.15 & 1.66 \\
\hline 11 & Ventilation in the vehicle & 8.10 & 1.86 \\
\hline 18 & Avoidance of traffic jam & 7.69 & 1.93 \\
\hline 1 & Enough place in the vehicle & 7.49 & 2.01 \\
\hline 5 & Fellow traveller cleanliness & 7.48 & 2.42 \\
\hline
\end{tabular}

Table 4. Comparison of results obtained by IPA and by state preference analysis

\begin{tabular}{cl|cl}
\hline No & \multicolumn{1}{c|}{ IPA } & No & \multicolumn{1}{c}{$\begin{array}{c}\text { State preference } \\
\text { analysis }\end{array}$} \\
\hline 21 & Punctuality & 21 & Punctuality \\
\hline 15 & Tickets price & 20 & Travel time \\
\hline 6 & Passenger politeness & 22 & Vehicle frequency \\
\hline 10 & $\begin{array}{l}\text { Cleanliness in the } \\
\text { vehicle }\end{array}$ & 10 & $\begin{array}{l}\text { Cleanliness in the } \\
\text { vehicle }\end{array}$ \\
\hline 17 & Waiting time at stop & 17 & Waiting time at stop \\
\hline 11 & $\begin{array}{l}\text { Ventilation in the } \\
\text { vehicle }\end{array}$ & 11 & $\begin{array}{l}\text { Ventilation in the } \\
\text { vehicle }\end{array}$ \\
\hline 18 & Avoidance of traffic jam & 18 & Avoidance of traffic jam \\
\hline 1 & $\begin{array}{l}\text { Enough place in the } \\
\text { vehicle }\end{array}$ & 1 & $\begin{array}{l}\text { Enough place in the } \\
\text { vehicle }\end{array}$ \\
\hline 5 & $\begin{array}{l}\text { Fellow traveller } \\
\text { cleanliness }\end{array}$ & 5 & $\begin{array}{l}\text { Fellow traveller } \\
\text { cleanliness }\end{array}$ \\
\hline
\end{tabular}

other element which makes difference is service quality element 6 (Passenger politeness). This can be explained by the fact that passenger car users do not consider politeness as an important criterion because they do not have the opportunity to have an unpleasant experience in this regard since they use the car.

If we return to results of the IPA after the introduction of the confidence interval only three elements remained in the Quadrant QIV outside the confidence interval. These are elements 11 (Ventilation in the vehicle), 10 (Cleanliness in the vehicle) and 15 (Tickets price). On the other hand it can be seen that among the first 9 elements in the state preference analysis are the elements 10 and 11. Action on these two elements would generate double effect. On the one hand, act on these two elements would increase the level of user satisfaction and impression of the improvement of the public transport system quality, while at the same time improvement of these elements would attract a certain number of public transport non-users.

In relation to the current economic situation in the country and limited resources for investment in public transport, authors find that in order to improve the public transport system quality from users and non-users point of view, improvements should start from these two elements.

\section{Conclusions}

Improvement of public transport system and attraction of large number of users are among the tasks that decision makers have in Belgrade. Certainly, there are many ways how it is possible to perform mentioned tasks. For example, purchase of new vehicles, infrastructure development, introduction of alternative transport modes, implementation of advanced technology would achieve the effect of improving the system, but the current economic situation does not allow for a large financial investment.

In order to consider how to improve the public transport system with minimal investment, it is necessary to determine what users and potential users mean by term 'the quality of public transport'. After determining which service quality elements are important to users but with which they are not satisfied, there is a possibility to act first on that elements. By acting on these elements users perceive improving of public transport service quality, and investment is lower. It would be ideal if decision makers could improve all elements of public transport service quality, but often this is not possible. Therefore, it is very important to identify the elements that should be primarily acted on and whose improvement would have the greatest impact on improving the quality of the transport system from user and non-user point of view.

Methodology that can be used for improving the public transport system service quality from users and non-users point of view, with minimal investment, is presented. Presented methodology identified the elements that should be primarily acted on. The methodology was tested on transport system users in Belgrade. Authors propose methodology that includes combination of importance performance analysis upgraded with confidence intervals and state preference analysis.

Based on the characteristics of the Belgrade public transport system, the authors' experience and relevant literature, 24 service quality elements were identified. For these elements transport system users were asked for opinion about level of importance and level of satisfaction.

Importance performance analysis singled out nine of twenty-four service quality elements as very important elements for users and elements for which users' satisfaction was very low. These elements are located in the Quadrant QIV (Concentrate here). Since this was the result from the sample, in order to reduce error that might occur when testing a new sample, the confidence interval was introduced. The purpose of introducing the confidence interval was to identify the elements that would be found in the Quadrant QIV (with a probability of $95 \%$ ) regardless of sample. Introduction of confidence intervals reduced the variability and assisted the decision maker to make effective conclusions. After the introduction of confidence interval, three elements singled out. Elements 11 (Ventilation in the vehicle), 10 (Cleanliness in the vehicle) and 15 (Tickets price) remained in Quadrant QIV. It is shown that, from the perspective of 
public transport users, process of public transport system improvement should start with acting on these three elements.

One of the strategic objectives of the transport system in Belgrade is to attract new users to public transport and relieve the transport network of passenger car users. Public transport users and non-users do not perceive service quality elements of public transport on the same way. Those who have access to a personal vehicle are expected to weigh the benefits of taking public transport relative to the convenience of driving.

In order to determine whether improvements of identified elements can help in popularization of public transport, non-users were surveyed in the state preference analysis. The respondents were asked about their preference for switching to the public transport system in case that any of the 24 service quality elements would be improved to a satisfactory level. When authors analysed overlapping of IPA and SP analysis results, they found two elements: 10 (Cleanliness in the vehicle) and 11 (Ventilation in the vehicle). In the case of IPA, these elements were in the Quadrant QIV after the introduction of the confidence interval, while in the case of state preference analysis, these elements have been ranked among the best.

It turns out that elements that are the most important from user and non-users point of view are elements that belong to the set of tangibles. Tangible dimension is known as dimension responsible for creating the first hand impressions. Some other service quality elements of listed 24 might have a higher priority from the perspective of traffic engineers, but the transport system customer perception about the quality of public transport system gave this result. The most important thing for the public transport system is that user satisfaction and user impression of the system quality are at a high level.

Applied methodology showed that improvement of these elements (cleanliness in the vehicle and ventilation in the vehicle) will give double effect. On the one hand improvement of these two elements would increase the level of users' satisfaction and impression of the improvement of the public transport system quality. On the other hand, improvement of these elements would attract a certain number of private car users to start using public transport. These are elements with whose improvement the process of public transport service quality improvement, from users and non-users point of view should start.

This type of research, which is related to tested users' perception of a certain transport system quality indicators, is very useful for system managers and decision makers, as it indicates which elements should be acted on in order to improve the quality of the transport system and make it sustainable.

\section{Acknowledgements}

This paper is a part of the project funded by the Ministry of Science and Technological Development of the Republic of Serbia, Project number: TR36021.

\section{References}

Beale, J. R.; Bonsall, P. W. 2007. Marketing in the bus industry: a psychological interpretation of some attitudinal and behavioural outcomes, Transportation Research Part F: Traffic Psychology and Behaviour 10(4): 271-287. http://dx.doi.org/10.1016/j.trf.2006.11.001

Chen, C.-F. 2008. Investigating structural relationships between service quality, perceived value, satisfaction, and behavioral intentions for air passengers: evidence from Taiwan, Transportation Research Part A: Policy and Practice 42(4): 709-717. http://dx.doi.org/10.1016/j.tra.2008.01.007

Chen, C.-F.; Chao, W.-H. 2011. Habitual or reasoned? Using the theory of planned behavior, technology acceptance model, and habit to examine switching intentions toward public transit, Transportation Research Part F: Traffic Psychology and Behaviour 14(2): 128-137.

http://dx.doi.org/10.1016/j.trf.2010.11.006

Dell'Olio, L.; Ibeas, A.; Cecín, P. 2011. The quality of service desired by public transport users, Transport Policy 18(1): 217-227. http://dx.doi.org/10.1016/j.tranpol.2010.08.005

Dell'Olio, L.; Ibeas, A.; Cecín, P. 2010. Modelling user perception of bus transit quality, Transport Policy 17(6): 388-397. http://dx.doi.org/10.1016/j.tranpol.2010.04.006

Deng, W.-J.; Kuo, Y.-F.; Chen, W.-C. 2008. Revised importance-performance analysis: three-factor theory and benchmarking, The Service Industries Journal 28(1): 37-51. http://dx.doi.org/10.1080/02642060701725412

Eskildsen, J. K.; Kristensen, K. 2006. Enhancing importanceperformance analysis, International Journal of Productivity and Performance Management 55(1): 40-60. http://dx.doi.org/10.1108/17410400610635499

Gotlieb, J. B.; Grewal, D.; Brown, S. W. 1994. Consumer satisfaction and perceived quality: complementary or divergent constructs?, Journal of Applied Psychology 79(6): 875-885. http://dx.doi.org/10.1037/0021-9010.79.6.875

Haeryip, S.; Yuhazri, M. Y.; Yahaya, S. H.; Myia Yuzrina, Z. A.; Ainul Azniza, A. Z. 2012. Revisited the importance and performance analysis (PA) and Kano model for customer satisfaction measurement, Global Engineers and Technologist Review 2(1): 22-39.

Joppe, M.; Martin, D. W.; Waalen, J. 2001. Toronto's image as a destination: a comparative importance-satisfaction analysis by origin of visitor, Journal of Travel Research 39(3): 252-260. http://dx.doi.org/10.1177/004728750103900302

Jović, J. 2000. Modal split modelling - some experience, in Urban Transport Systems: Proceedings from the 2nd KFB Research Conference, 7-8 June 1999, Lund, Sweden, 533-541.

Jović, J. 1992. Uticaj ponašanja korisnika na planiranje raspodele putovanja po načinu prevoza: $\mathrm{PhD}$ Thesis, University of Belgrade. (in Serbian).

Kittelson \& Associates, Inc. 1999. Transit Capacity and Quality of Service Manual. TCRP Web Document 6 (Project A-15). Contractor's Final Report. Transportation Research Board, National Research Council, Washington, D.C. 62 p. Available from Internet: http://onlinepubs.trb.org/onlinepubs/ tcrp/tcrp_webdoc_6-a.pdf

Kroes, E. P.; Sheldon, R. J. 1988. Stated preference methods: an introduction, Journal of Transport Economics and Policy 22(1): 11-25.

Lai, W.-T., Chen, C.-F. 2011. Behavioral intentions of public transit passengers - the roles of service quality, perceived value, satisfaction and involvement, Transport Policy 18(2): 318-325. http://dx.doi.org/10.1016/j.tranpol.2010.09.003 
Martilla, J. A.; James, J. C. 1977. Importance-performance analysis, Journal of Marketing 41(1): 77-79. http://dx.doi.org/10.2307/1250495

Matzler, K.; Sauerwein, E.; Heischmidt, K. A. 2003. Importance-performance analysis revisited: the role of the factor structure of customer satisfaction, The Service Industries Journal 23(2): 112-129. http://dx.doi.org/10.1080/02642060412331300912

Parasuraman, A.; Zeithaml, V. A.; Berry, L. L. 1985. A conceptual model of service quality and its implications for future research, Journal of Marketing 49 (4): 41-50. http://dx.doi.org/10.2307/1251430

Ryus, P.; Ausman, J.; Teaf, D.; Cooper, M.; Knoblauch, M. 2000. Development of Florida's transit level-of-service indicator, Transportation Research Record 1731: 123-129. http://dx.doi.org/10.3141/1731-15

Slack, N. 1994. The importance-performance matrix as a determinant of improvement priority, International Journal of Operations \& Production Management 14(5): 59-75. http://dx.doi.org/10.1108/01443579410056803

TRB. 2003. Transit Capacity and Quality of Service Manual. Transit Cooperative Research Program, TCRP Report 100. 2nd edition. Transport Research Board (TRB). Available from Internet: http://www.trb.org/Main/Blurbs/153590. aspx

Watson, P. L. 1974. The Value of Time: Behavioral Models of Modal Choice. Lexington Books. 170 p.

Wu, H.-H.; Shieh, J.-I. 2009. The development of a confidence interval-based importance-performance analysis by considering variability in analyzing service quality, Expert Systems with Applications 36(3): 7040-7044. http://dx.doi.org/10.1016/j.eswa.2008.08.055

Wu, H.-H.; Tang, Y.-T.; Shyu, J.-W. 2010. A case of applying importance-performance analysis in identifying key success factors to develop marketing strategies, Quality \& Quantity 44(6): 1207-1218. http://dx.doi.org/10.1007/s11135-009-9262-7

Yang, L.-J.; Chou, T.-C.; Ding, J.-F. 2011. Using the Importance-Performance Analysis (IPA) approach to measure the service quality of mobile application stores in Taiwan, African Journal of Business Management 5(12): 4824-4834. http://dx.doi.org/10.5897/AJBM10.1163

Zhao, F.; Li, M.-T.; Chow, L.-F.; Gan, A.; Shen, L. D. 2002. FSUTMS Mode Choice Modeling: Factors Affecting Transit Use and Access. Report No. NCTR 392-07, 416-03. National Center for Transit Research (NCTR) at the Center for Urban Transportation Research (CUTR), University of South Florida, Tampa, Florida. 161 p. Available from Internet: http://www.dot.state.fl.us/research-center/Completed_ Proj/Summary_PTO/FDOT_BC137_07_rpt.pdf 